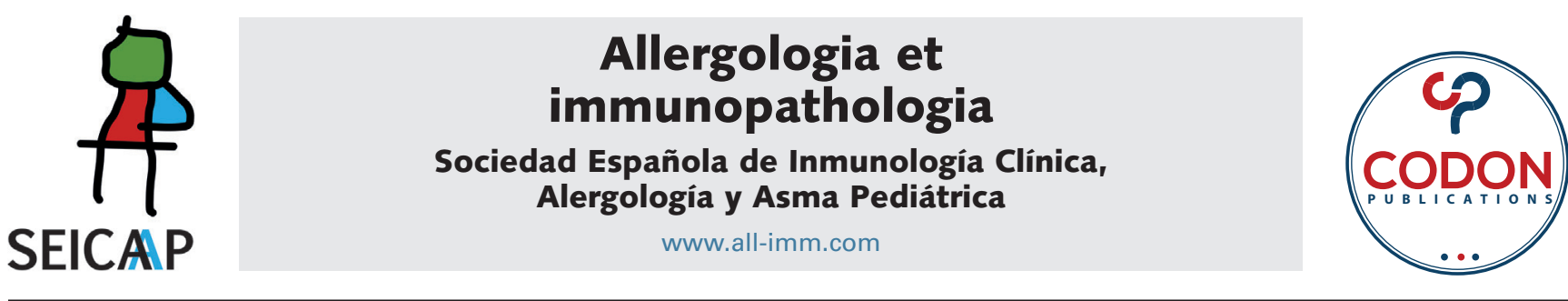

\title{
Mite allergen avoidance decreases allergic symptoms in children in Ishinomaki city of Japan after natural disasters
}

\author{
Chiyako Oshikataa,b, Maiko Watanabe ${ }^{\mathrm{c}}$, Kazuhiro Hashimoto ${ }^{\mathrm{d}}$, Akiko Yamazakie,

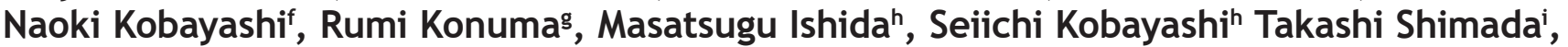 \\ Takeshi Kaneko $^{b}$, Yoichi Kamataj, Shinichi Kuriyama ${ }^{k, l}$, Shigeo Kure ${ }^{m}$, Masaru Yanai ${ }^{h}$, \\ Naomi Tsurikisawa ${ }^{\mathrm{a}, \mathrm{b} *}$
}

\author{
aDepartment of Allergy and Respirology, Hiratsuka City Hospital, Hiratsuka, Kanagawa, Japan \\ ${ }^{b}$ Department of Pulmonology, Yokohama City University Graduate School of Medicine, Kanazawa-ku, Yokohama, Kanagawa, Japan \\ 'Division of Microbiology, National Institute of Health Sciences, Kawasaki, Kanagawa, Japan \\ ${ }^{d}$ FCG Research Institute Inc., Koto-ku, Tokyo, Japan \\ ${ }^{e}$ Co-Department of Veterinary Medicine, Iwate University, Morioka, Iwate, Japan \\ fSchool of Life and Environmental Sciences, Azabu University, Chuo-ku, Sagamihara, Kanagawa, Japan \\ 'Tokyo Metropolitan Industrial Technology Research Institute, Koto-ku, Tokyo, Japan \\ hDepartment of Respiratory Medicine, Japanese Red Cross Ishinomaki Hospital, Hebita, Ishinomaki, Miyagi, Japan \\ iNichinichi Pharmaceutical Co. Ltd., Iga, Mie, Japan \\ ${ }^{j}$ Faculty of Life Science, Senri Kinran University, Suita, Osaka, Japan \\ ${ }^{k}$ Tohoku University Graduate School of Medicine, Aobaku, Sendai, Miyagi, Japan \\ 'Tohoku University International Research Institute of Disaster Science, Aobaku, Sendai, Miyagi, Japan \\ mDepartment of Pediatrics, Tohoku University School of Medicine, Aobaku, Sendai, Miyagi, Japan
}

Received 21 November 2021; Accepted 13 January 2022

Available online 1 March 2022

\section{KEYWORDS}

allergen avoidance;

allergic rhinitis;

asthma;

atopic dermatitis;

Dermatophagoides

farina;

Great East Japan

Earthquake

\begin{abstract}
Objective: We investigated the prevalence of asthma, rhinitis, and atopic dermatitis in children, evaluated the mite allergen levels in their bedding after the Great East Japan Earthquake, and assessed changes in allergic symptoms in children and their families after allergen avoidance practices.

Methods: We performed a survey for the International Study of Asthma and Allergies in Childhood (ISAAC) comprising 1109 children, aged 7-8 years, living in Ishinomaki, Japan. We collected responses from 464 children, and in 2016, measured the level of Dermatophagoides group 1 (Der 1 ) in the bedding of 202 of these children. The intervention group of children attended at least one allergen avoidance seminar. The levels of Der 1 in their bedding were measured, along with changes in allergic symptoms, in 17 children in 2017 and 14 children in 2018. The nonintervention group comprised children who did not attend an allergen avoidance seminar at any time.
\end{abstract}

*Corresponding author: Naomi Tsurikisawa, MD, Department of Allergy and Respirology, Hiratuska City Hospital, 1-19-1 Minamihara, Hiratsuka, Kanagawa 254-0065, Japan. Email address: User831328@aol.com 
Results: Of the 464 children who participated in the ISAAC, 50 (10.8\%) reported having asthma, 179 (38.8\%) allergic rhinitis, and $126(27.3 \%)$ atopic dermatitis. The average level of Der 1 measured in the bedding of the 202 children in 2016 was $295.8 \mathrm{ng} / \mathrm{m}^{2}$. The levels of Der 1 in the intervention group-but not in the nonintervention group-significantly decreased in 2017 and 2018. The symptoms of asthma, allergic rhinitis, and atopic dermatitis in the children of intervention group and their families decreased after allergen avoidance practices.

Conclusions: Allergen avoidance practices relieved allergic symptoms in school children after the Great East Japan Earthquake.

(c) 2022 Codon Publications. Published by Codon Publications.

\section{Introduction}

The increased environmental humidity that follows natural disasters such as floods and tsunamis supports the rapid multiplication of fungi and bacteria, resulting in infectious diseases and the exacerbation of asthma., ${ }^{1,2}$ For example, the levels of airborne fungi have increased inside dwellings in Fukushima, Japan, since the 2011 Great East Japan Earthquake, ${ }^{3}$ and various species of mites, which are otherwise well-known triggers of allergy and asthma, feed on fungi. ${ }^{4}$ In addition, we have already reported a rare patient of allergic bronchopulmonary mycosis who was exposed to Eurotium herbariorum while residing in post-earthquake temporary housing in the city of Ishinomaki. ${ }^{5}$

The prevalence of bronchial asthma and atopic dermatitis in children increased after the Great East Japan Earthquake and the resulting tsunami. ${ }^{6,7}$ Ishinomaki, located in eastern Miyagi Prefecture, was damaged by the large tsunami, which increased development and exacerbation of asthma in adults. ${ }^{8,9}$ We reported that mass screening for respiratory and allergic diseases revealed a $24 \%$ prevalence of asthma among adults who have been living in temporary dwellings in Ishinomakior since 2014. In addition, Ishinomaki residents diagnosed with asthma confirmed mite-specific immunoglobulin E (IgE) antibody titers that were higher than Aspergillus-specific IgE antibody titers. ${ }^{9}$

Whether the prevalence of allergic diseases in children in Ishinomaki has increased since the earthquake is not known. Currently, there are no reports of mite allergen levels in bedding within the disaster area, or of the effects of post-earthquake allergen avoidance practices on allergic symptoms in children.

Several reports have supported the efficacy of allergen avoidance in children. ${ }^{10,11}$ However, the Global Initiative for Asthma's (GINA) guidelines do not recommend allergen avoidance as a general strategy in asthma patients. ${ }^{12}$ There is limited evidence of clinical benefits for sensitized children with asthma who use multi-component avoidance strategies, although there is limited evidence of clinical benefits for asthma patients who use single-strategy indoor allergen avoidance techniques..$^{12-14}$

We demonstrated that using environmental interventions, based on a 32-task checklist for allergen avoidance, was associated with reduced levels of Dermatophagoides group 1 (Der 1) in the bedding of adult asthma patients. ${ }^{15}$ In addition, asthma symptoms decreased, minimum peak expiratory flow levels increased, and decrease was observed in fractional exhaled nitric oxide levels. ${ }^{16}$
In the current study, we performed a survey for the International Study of Asthma and Allergies in Childhood $(\text { ISAAC })^{17}$ in Ishinomaki, Japan, comprising 7-8-year-old children, to investigate the prevalence of asthma, allergic rhinitis, and atopic dermatitis after the Great East Japan Earthquake. Some of the children, along with their parents, received individualized guidance on allergen avoidance according to the 32-task checklist. We investigated changes in the Der 1 level in the bedding (futons or mattresses) and allergic symptoms of the children, their parents, and their siblings after an intervention of allergen avoidance practices.

\section{Subjects and methods}

\section{Study population}

As a study site, we selected Ishinomaki in the Miyagi Prefecture, which had not been surveyed as of 2016, although the Miyagi Prefecture had been targeted in other health surveys of children after the Great East Japan Earthquake. ${ }^{6,718}$ In July 2016, we conducted an ISAAC survey in Ishinomaki comprising 1109 7-8-year old second-grade children and collected responses from 464 children. ${ }^{17}$

\section{Survey details}

Of the 464 children who participated in the ISAAC questionnaire, we evaluated the levels of Der 1 on the mattresses or futons of 202 children in September or October 2016. We reported the results of the bedding Der 1 level to the children and parents and presented at the allergen avoidance seminar. Attendance in the seminar, held thrice a year until September 2018, by the children and their parents was voluntary. The intervention group consisted of 17 children who attended at least one allergen avoidance seminar and had the levels of bedding Der 1 measured in September 2017. The nonintervention group was decided by the parents' individual decision. The nonintervention group consisted of 17 children who did not attend any allergen avoidance seminar and had the levels of bedding Der 1 measured in September 2017. A final measurement of bedding Der 1 level of 14 children in the intervention group and nine children in the nonintervention group was conducted in September 2018 (Figure 1).

Prior to attending any intervention seminar and until September 2018 thrice a year, the children in the 


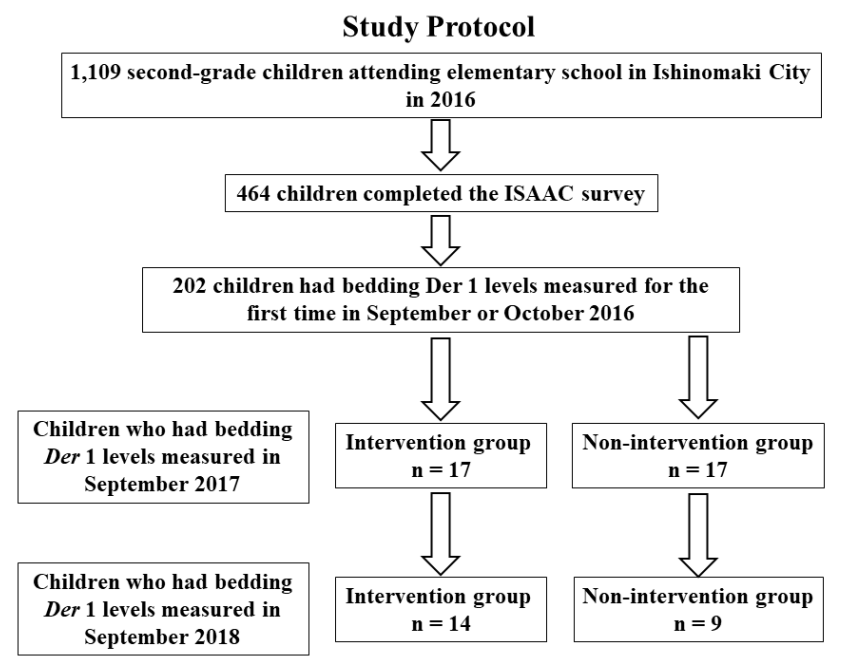

Figure 1 Study protocol. Flow diagram illustrating the progress of patients during this study.

intervention group, their parents, and their siblings were evaluated in terms of their allergic symptoms for asthma, allergic rhinitis, and atopic dermatitis by visual analog scale (VAS). ${ }^{19}$

\section{Ethics}

The hospital ethics committee at our hospital approved the study in accordance with the Helsinki Declaration. Written informed consent was obtained from all patients or their legal representatives. The ethics approval number was R2016-06 at the National Hospital Organization Saitama Hospital and 30-006 at the Hiratsuka City Hospital.

\section{Measurements}

\section{Questionnaire}

The questionnaire consisted of an ISAAC survey regarding the presence or absence of wheezing, asthma, allergic rhinitis, and atopic eczema. ${ }^{17}$ The questionnaire also included questions about allergic diseases of family members, the damage to their home caused by the earthquake, and their current residence.

\section{Visual analog scale}

The authors created the following new VAS for the degree of allergic symptoms with reference to the report presented by Stewart et al. ${ }^{19}$ : In particular, 10: I have some symptoms every day, and it is a big hindrance to my life; 9: I have some symptoms every day and have some trouble in my life; 8: I have symptoms almost every day, but there are days when I don't really care; 7: I have symptoms almost every day, but there are many days when I don't care much; 6: I have about half of the symptoms every week; 5: I have symptoms for at least one day of the week; 4: There are 3 or more days of the week with symptoms but there are weeks with no symptoms; 3: There is 1 day in a week with symptoms but there are weeks with no symptoms; 2: I have symptoms for several days in a month; 1: I may have very few symptoms in a month; 0 : No symptoms at all in a month.

\section{Measurement of Dermatophagoides group 1 level on futon or mattress}

Bedroom dust samples were collected on an adhesive tape; tape pieces were placed into a polystyrene tube $(10 \times 70 \mathrm{~mm})$ and then extracted with $2 \mathrm{~mL}$ of phosphate buffer solution (PBS) containing 0.2\% (v/v) Tween 20, $0.2 \%(\mathrm{w} / \mathrm{v})$ bovine serum albumin (BSA), and $0.05 \%(\mathrm{w} / \mathrm{v})$ sodium azide (PBS-T-BSA) by placing these on an orbital shaker overnight at room temperature. Samples on adhesive tape with a ratio of $1: 100 \mathrm{w} / \mathrm{v}(20 \mathrm{mg}$ in $2 \mathrm{~mL})$ PBS-TBSA were extracted for $4 \mathrm{~h}$ at room temperature. Levels of Dermatophagoides pteronyssinus 1 (Der $\mathrm{p}$ 1) or $D$. farina 1 (Der $f 1$ ) were quantified by using a previously developed fluorometric enzyme-linked-immunosorbent serologic assay (ELISA). ${ }^{20,21}$ Results were expressed as nanograms of allergen $/ \mathrm{m}^{2}$ on adhesive tape according to the method described by Yasueda et al. ${ }^{21}$ Inter-sample variations were accounted for by averaging the results from two adhesive tape samples.

\section{Allergen avoidance strategy}

In March 2017, the 17 participants of the intervention group received microfiber covers (Microgard, Yasaka Co., Chiba, Japan) to place on their pillows and futons or mattresses. Participants were instructed on allergen avoidance strategy according to a checklist that included 32 techniques across the following five sections-1: humidity countermeasures, 2: control of sources of Der 1 pollution, 3: overall management of bedding, 4: maintenance of futons or beds, and 5: efficient cleaning of bedrooms. ${ }^{15}$ In addition to these interventions, we held an environment improvement seminar thrice a year, during each of which we addressed mite allergen avoidance according to the 32-item checklist and gave participants the results of their health examination. ${ }^{15}$

\section{Statistical analysis}

All values are expressed as mean \pm SD or median \pm standard error of mean (SEM), unless otherwise specified. Data from two groups were compared statistically by using the MannWhitney U-test; comparison of groups by using two-way ANOVA with repeated measures, or with Chi-square test, revealed no significant differences between the two values. Mean values for data obtained at seasonal time points, before and after intervention, or at first and final examinations, were compared by using the Wilcoxon matched pairs t-test; $P>0.05$ were considered statistically significant. All statistical analyses were performed by using the SPSS for Windows, version 20 (SPSS, Chicago, IL, USA). 


\section{Results}

A total of 464 children were recruited to participate in the ISAAC survey, and measured the bedding Der 1 level of 34 of these children in the fall of 2016 and 2017. We compared the ISAAC survey results of these 34 children with those of the 430 children who did not have bedding Der 1 level quantified (Table 1).

Overall, $49.1 \%$ of the 464 participants were males, 50 (10.8\%) had asthma, 179 (38.8\%) had allergic rhinitis, and

Table 1 A total of 464 children participated in the ISAAC survey. Of these participants, 34 children having bedding Der 1 level measured in the fall of 2016 and 2017 were compared with children who did not have bedding Der 1 level quantified in terms of allergic disease characteristics.

\begin{tabular}{|c|c|c|c|c|}
\hline & $\begin{array}{c}\text { Characteristics } \\
\text { of all } \\
\text { students who } \\
\text { participated } \\
\text { in the ISAAC } \\
\text { survey }\end{array}$ & $\begin{array}{l}\text { Children who } \\
\text { had bedding } \\
\text { Der } 1 \text { level } \\
\text { measured in } \\
\text { the fall of } 2016 \\
\text { and } 2017\end{array}$ & $\begin{array}{l}\text { Children who } \\
\text { participated in } \\
\text { the ISAAC survey } \\
\text { but did not have } \\
\text { bedding Der } 1 \\
\text { level measured }\end{array}$ & $\begin{array}{c}\text { Comparison } \\
\text { between } \\
\text { children who did } \\
\text { and did not have } \\
\text { bedding Der } 1 \\
\text { level measured }\end{array}$ \\
\hline & $n=464$ & $\mathrm{n}=34$ & $\mathrm{n}=430$ & $\mathbf{P}$ \\
\hline Gender (male/female, $\mathrm{n}$ ) & $228 / 236$ & $21 / 13$ & $207 / 223$ & NS \\
\hline \multicolumn{5}{|l|}{ Prevalence based on ISAAC } \\
\hline Asthma Yes/No, (\%) & $50 / 414(10.8 \%)$ & $8 / 26(23.5 \%)$ & $42 / 388(9.8 \%)$ & $<0.05$ \\
\hline Allergic rhinitis Yes/No (\%) & $179 / 282(38.8 \%)$ & $23 / 11(67.6 \%)$ & $156 / 271(36.5 \%)$ & $<0.01$ \\
\hline Atopic dermatitis Yes/No (\%) & $126 / 335(27.3 \%)$ & $16 / 18(47.1 \%)$ & $112 / 316(26.2 \%)$ & $<0.05$ \\
\hline \multicolumn{5}{|c|}{ Onset of allergic disease according to doctor's diagnosis } \\
\hline Asthma, mean \pm SD $(y)(n)$ & $2.9 \pm 1.8(n=43)$ & $2.6 \pm 1.2(n=7)$ & $3.0 \pm 1.9(n=36)$ & NS \\
\hline Allergic rhinitis, mean \pm SD (y) (n) & $4.6 \pm 2.0(n=70)$ & $3.8 \pm 2.5(n=8)$ & $4.7 \pm 2.0(n=62)$ & NS \\
\hline Atopic dermatitis, mean \pm SD (y) (n) & $2.6 \pm 2.4(n=66)$ & $1.9 \pm 1.6(n=11)$ & $2.8 \pm 2.5(n=55)$ & NS \\
\hline Food allergy, mean \pm SD $(y)(n)$ & $1.9 \pm 2.2(n=20)$ & $1.7 \pm 2.1(n=3)$ & $1.9 \pm 2.3(n=17)$ & NS \\
\hline \multicolumn{5}{|l|}{ Family history of asthma } \\
\hline Mother or father, n (\%) & $58 / 406(12.5 \%)$ & $9(26.5 \%)$ & $49(11 / 4 \%)$ & 0.01 \\
\hline Siblings, $n(\%)$ & $51 / 413(11.0 \%)$ & $6(17.6 \%)$ & $45(10.5 \%)$ & NS \\
\hline Grandmother or grandfather, n (\%)) & $10 / 454(2.2 \%)$ & $1(2.9 \%)$ & $9(2.1 \%)$ & NS \\
\hline \multicolumn{5}{|l|}{ Family history of allergic rhinitis } \\
\hline Mother or father, $\mathrm{n}(\%)$ & $108 / 356(23.3 \%)$ & $15(44.1 \%)$ & $93(21.6 \%)$ & $<0.01$ \\
\hline Brothers, $\mathrm{n}(\%)$ & $84 / 380(18.1 \%)$ & $9(26.5 \%)$ & $75(17.4 \%)$ & NS \\
\hline Grandmother or grandfather, n (\%)) & $5 / 459(1.1 \%)$ & $2(5.9 \%)$ & $3(0.7 \%)$ & $<0.01$ \\
\hline \multicolumn{5}{|l|}{ Family history of atopic dermatitis } \\
\hline Mother or father, $\mathrm{n}(\%)$ & $53 / 411$ (11.4\%) & $10(29.4 \%)$ & $43(10.0 \%)$ & $<0.01$ \\
\hline Brothers, n (\%) & $61 / 403(15.1 \%)$ & $6(17.6 \%)$ & $55(12.8 \%)$ & NS \\
\hline Grandmother or grandfather, $\mathrm{n}(\%)$ & $4 / 460(0.9 \%)$ & $1(2.9 \%)$ & $3(0.7 \%)$ & NS \\
\hline $\begin{array}{l}\text { Smoking history of mother or father } \\
\text { (never-smoker/ex-smoker/current smoker) }\end{array}$ & $190 / 63 / 211$ & $18 / 5 / 11$ & $172 / 58 / 200$ & NS \\
\hline Extent of damage to home in the earthquake & & & & NS \\
\hline Completely destroyed, n (\%) & $101(21.8 \%)$ & $7(20.6 \%)$ & 94 (21.9\%) & \\
\hline Large-scale half-destroyed, n (\%) & $81(17.5 \%)$ & $5(14.7 \%)$ & $76(17.7 \%)$ & \\
\hline Half destroyed, n (\%) & $16(3.5 \%)$ & 0 & $16(3.7 \%)$ & \\
\hline Partially damaged, n, (\%) & $170(36.7 \%)$ & $13(38.2 \%)$ & $157(36.6 \%)$ & \\
\hline No damage, $n,(\%)$ & $82(17.7 \%)$ & $9(26.5 \%)$ & $73(17.0 \%)$ & \\
\hline No residence, $\mathrm{n}(\%)$ & $13(2.8 \%)$ & 0 & $13(3.0 \%)$ & \\
\hline Relocation after the earthquake (yes/no) & $223 / 237$ (48.5\%) & $14(41.2 \%)$ & $209(49.1 \%)$ & NS \\
\hline Residence at the time of the survey $(n=463)$ & & & & NS \\
\hline Temporary housing, $\mathrm{n}(\%)$ & $13(2.8 \%)$ & $1(2.9 \%)$ & $12(2.8 \%)$ & \\
\hline $\begin{array}{l}\text { New detached house after the earthquake, } \\
n(\%)\end{array}$ & $112(24.2 \%)$ & $12(35.3 \%)$ & $100(23.3 \%)$ & \\
\hline Rental housing, n (\%) & $104(22.5 \%)$ & $6(17.6 \%)$ & $98(22.8 \%)$ & \\
\hline $\begin{array}{l}\text { Lived in a relative's residence after the } \\
\text { earthquake, } n(\%)\end{array}$ & $23(5.0 \%)$ & $1(2.9 \%)$ & $22(5.1 \%)$ & \\
\hline $\begin{array}{l}\text { A house that have lived in since before the } \\
\text { earthquake, } n(\%)\end{array}$ & $211(45.6 \%)$ & $14(41.2 \%)$ & 197 (45.9\%) & \\
\hline Age of house, mean \pm SD $(y)$ & $14.6 \pm 16.1$ & $11.0 \pm 11.4$ & $15.0 \pm 16.5$ & NS \\
\hline
\end{tabular}


$126(27.3 \%)$ had atopic dermatitis. The average age of onset was $2.9 \pm 1.8$ years for asthma, $4.6 \pm 2.0$ years for allergic rhinitis, and $2.6 \pm 2.4$ years for atopic dermatitis. The number of children with a family history (either the mother or father) of having: asthma was 58 (12.5\%), allergic rhinitis was $108(23.3 \%)$, and atopic dermatitis was 53 (11.4\%). The prevalence of asthma $(P<0.05)$, allergic rhinitis ( $P$ $<0.01)$, and atopic dermatitis $(P<0.05)$ was significantly increased in children who had bedding Der 1 levels measured compared with children who did not have bedding Der 1. An allergic history of asthma, allergic rhinitis, and atopic dermatitis was significantly increased in mothers or fathers whose children had bedding Der 1 levels measured compared with parents whose children had no bedding Der $1(\mathrm{P}<0.01)$.

In all, $39.3 \%$ of the children who participated in this study had their homes completely destroyed or had homes that underwent large-scale partial destruction because of the Great East Japan Earthquake. Of the 460 children surveyed, 223 (48.5\%) had moved more than once after the earthquake, and $45.6 \%$ of the children were living continuously in the same house since before the earthquake (Table 1). At the time of the survey, 5 years after the earthquake, $2.8 \%$ of children lived in temporary housing, $24.2 \%$ in newly built housing, and $22.5 \%$ in rented housing.

According to the ISAAC survey, the prevalence of asthma, allergic rhinitis, and atopic dermatitis did not differ significantly between the intervention and nonintervention groups (Table 2). Allergic rhinitis is seasonal and often exacerbates in the fall. Family history of asthma and allergic rhinitis was not significantly different between the intervention and nonintervention groups, but the parents in the intervention group had a significantly increased history of atopic dermatitis compared to the nonintervention group $(P<0.05)$ (Table 2$)$. There were no significant differences between the two groups in terms of parents' tobacco use, relocation after the earthquake, or the length of time at their current residence.

The average Der 1 level in the bedding of 202 children in September or October 2016 was $295.8 \mathrm{ng} / \mathrm{m}^{2}$. Comparing the average Der 1 levels measured in the bedding of 34 children in 2016 and 2017 with those of 168 children in 2016 revealed no significant difference $\left(233.9 \mathrm{ng} / \mathrm{m}^{2}\right.$ vs. 298.5 $\mathrm{ng} / \mathrm{m}^{2}$ ) (data not shown).

The average Der 1 level measured in September or October 2016 did not differ between the intervention group $\left(239.7 \mathrm{ng} / \mathrm{m}^{2}\right)$ and the nonintervention group $\left(212.9 \mathrm{ng} / \mathrm{m}^{2}\right)$ (Figure 2a). In the intervention group, bedding Der 1 level decreased from September or October 2016 to September 2017 for 16 of the 17 children $(P<0.01)$. However, in the nonintervention group, bedding Der 1 level did not significantly change from 2016 to 2017(Figure 2a).

According to the VAS, the symptoms of asthma $(P<$ 0.01), allergic rhinitis $(P<0.05)$, and atopic dermatitis $(P$ $<0.05)$ in children of the intervention group significantly decreased from September or October 2016 to September 2017 (Figure 2b).

Table 2 Comparison between the intervention group that participated in mite allergen avoidance survey and the nonintervention group.

\begin{tabular}{|c|c|c|c|}
\hline & Intervention group & Nonintervention group & \\
\hline & $\mathrm{n}=17$ & $\mathrm{n}=17$ & $\mathrm{P}$ \\
\hline Gender (male/female, $\mathrm{n}$ ) & $10 / 7$ & $11 / 6$ & NS \\
\hline \multicolumn{4}{|l|}{ Prevalence based on the ISAAC survey } \\
\hline Asthma, yes/no (\%) & $6 / 11(35.3 \%)$ & $2 / 15(11.8 \%)$ & NS \\
\hline Allergic rhinitis, yes/no (\%) & $12 / 5(70.6 \%)$ & $11 / 6(64.7 \%)$ & NS \\
\hline Atopic dermatitis, yes/no (\%) & $9 / 8(52.9 \%)$ & $6 / 11(35.3 \%)$ & NS \\
\hline \multicolumn{4}{|l|}{ Onset of Allergic disease based on doctors' diagnosis } \\
\hline Asthma mean \pm SD (y) (n) & $2.8 \pm 1.5(n=5)$ & $2.0 \pm 0(n=2)$ & \\
\hline Allergic rhinitis mean \pm SD $(y)(n)$ & $3.8 \pm 2.5(n=6)$ & $3.5 \pm 3.5(n=2)$ & \\
\hline Atopic dermatitis mean \pm SD $(y)(n)$ & $1.2 \pm 0.8(n=5)$ & $2.5 \pm 2.0(n=6)$ & \\
\hline Food allergy mean \pm SD $(y)(n)$ & $0.5 \pm 0.7(n=2)$ & $4.0(n=1)$ & \\
\hline \multicolumn{4}{|l|}{ Family history of asthma } \\
\hline Mother or father, n (\%)) & $6 / 11(35.3 \%)$ & $3 / 14(17.6 \%)$ & NS \\
\hline Siblings, $\mathrm{n}(\%)$ & $4 / 13(23.5 \%)$ & $2 / 15(11.8 \%)$ & NS \\
\hline Grandmother or grandfather, $\mathrm{n}(\%)$ & $1 / 16(5.9 \%)$ & 0 & NS \\
\hline \multicolumn{4}{|l|}{ Family history of allergic rhinitis } \\
\hline Mother or father, $\mathrm{n}(\%)$ & $8 / 9(47.1 \%)$ & $7 / 10(41.2 \%)$ & NS \\
\hline Brothers, $\mathrm{n}(\%)$ & $5 / 12(29.4 \%)$ & $4 / 13(23.5 \%)$ & NS \\
\hline Grandmother or grandfather, n (\%) & $2 / 15(11.8 \%)$ & 0 & NS \\
\hline \multicolumn{4}{|l|}{ Family history of atopic dermatitis } \\
\hline Mother or father, $\mathrm{n}(\%))$ & $8 / 9(47.1 \%)$ & $2 / 15(11.8 \%)$ & $<0.05$ \\
\hline Brothers, n (\%) & $3 / 14(17.6 \%)$ & $3 / 14(17.6 \%)$ & NS \\
\hline $\begin{array}{l}\text { Smoking history of mother or father (never-smoker/ } \\
\text { ex-smoker/current smoker) }\end{array}$ & $8 / 4 / 5$ & $10 / 1 / 6$ & NS \\
\hline Relocation after the earthquake, yes/no (\%) & $7 / 10(41.2 \%)$ & $7 / 10(41.2 \%)$ & NS \\
\hline Age of house mean \pm SD $(y)$ & $10.6 \pm 12.2$ & $11.5 \pm 10.8$ & NS \\
\hline
\end{tabular}


(A) Intervention group

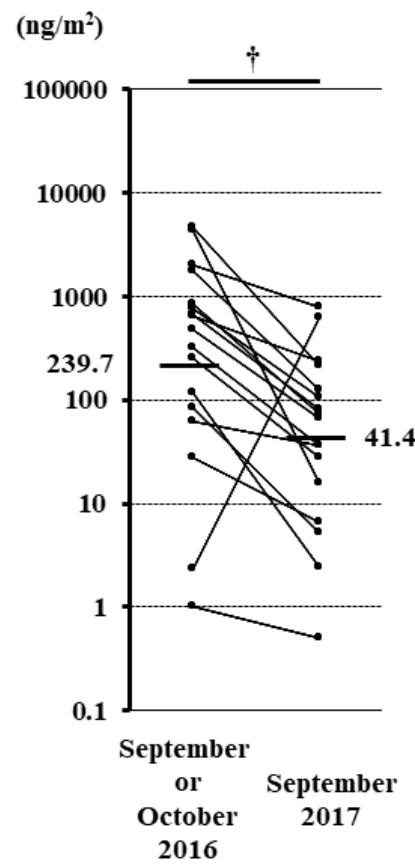

\section{Non-intervention group}

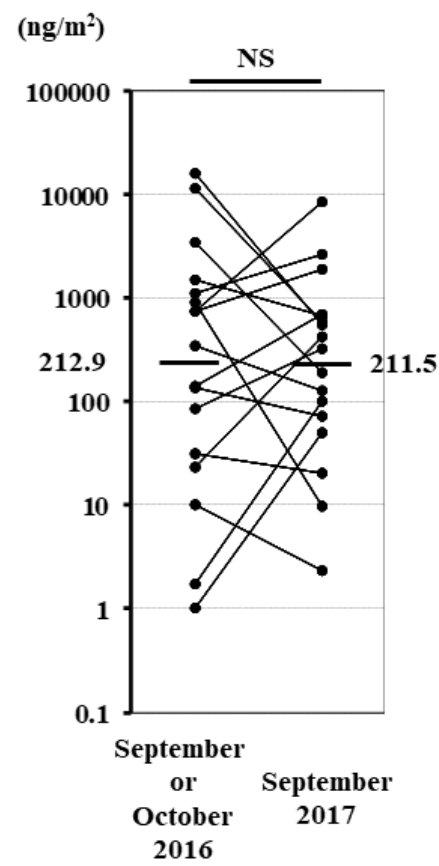

(B)

\section{Asthma}

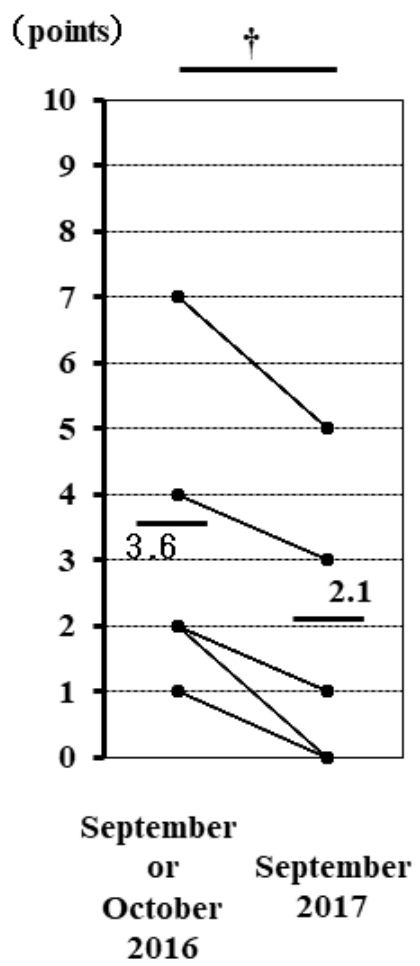

Allergic rhinitis

(points)

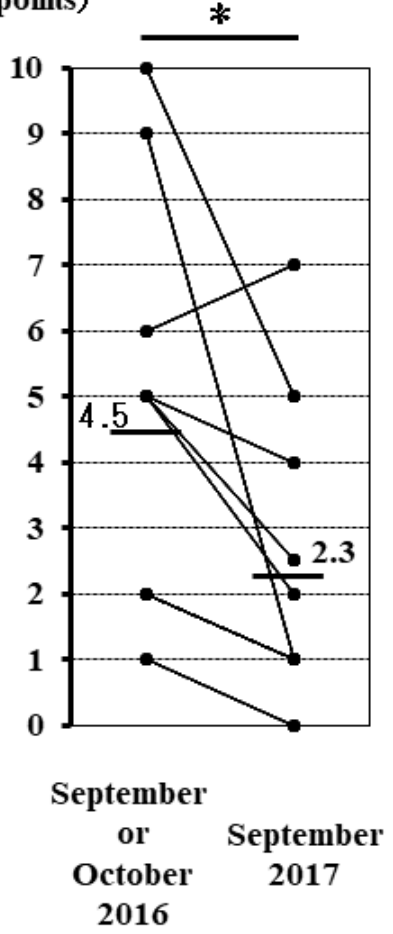

Atopic dermatitis

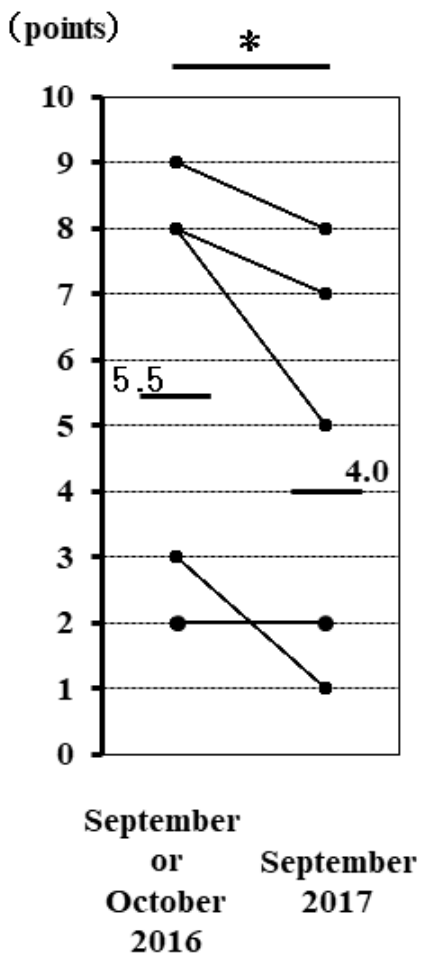

Figure 2 (A) Change in bedding Der 1 levels from 2016 to 2017 in intervention and nonintervention groups. (B) Change in allergic symptoms score for asthma, allergic rhinitis, and atopic dermatitis before and after intervention in the intervention group. ${ }^{\dagger} \mathrm{P}<0.01$; NS: not significant. 


\section{Intervention group}

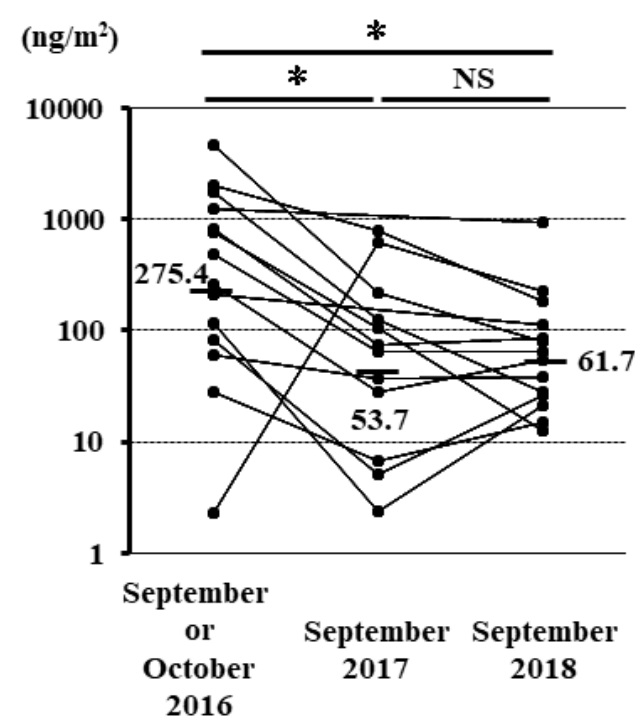

\section{Non-intervention group}

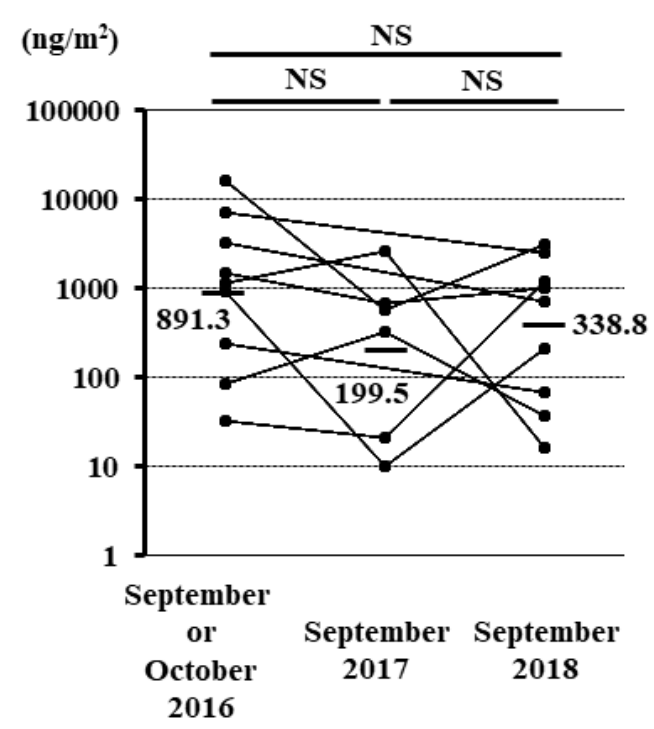

Figure 3 Changes in bedding Der 1 levels before allergen avoidance intervention and at 1 and 2 years after the initiation of allergen avoidance measures in intervention and nonintervention groups. ${ }^{*} \mathrm{P}<0.05$; NS: not significant.

In 2016 and 2018, the bedding Der 1 level was measured for 14 children in the intervention group and nine children in the nonintervention group. The parents in the intervention group attended the allergen avoidance seminars an average of 4.6 times over a 2-year period. The bedding Der 1 level in the intervention group decreased in the first year after intervention (2017) as well as in the second year (2018). However, the bedding Der 1 level in the nonintervention group did not change significantly from 2016 to 2018 (Figure 3).

According to the VAS, the symptoms of asthma, allergic rhinitis, and atopic dermatitis decreased from 2016 to 2018 in the children who participated in the study (Figure $4 a)$ and in their parents (Figure 4b) and siblings (Figure 4c). These effects were maintained for 2 years after the intervention.

\section{Discussion}

Noninfectious consequences of a flooding disaster are common and include miliaria, immersion foot syndromes, irritant and allergic contact dermatitis, traumatic wounds, animal bites, arthropod assault as well as exacerbation of existing skin conditions, such as atopic dermatitis, psoriasis, and alopecia areata, because of increased stress or nonavailability of daily medications. ${ }^{22}$

Owing to the size of the Great East Japan Earthquake and the resulting damage caused in Ishinomaki, the prevalence of allergic diseases and Der 1 level on the mattresses or futons of children from this city were investigated. We have already reported that in Kanagawa during the autumn, the average Der 1 level on the mattresses and futons of adult patients with asthma was $44.8 \mathrm{ng} / \mathrm{m}^{2}$ and $45.0 \mathrm{ng} / \mathrm{m}^{2}$, respectively. ${ }^{15,16} \mathrm{In}$ the current study, the mean Der 1 level on the mattresses or futons of children, measured in September or October 2016 in Ishinomaki after the Great East Japan Earthquake, exceeded $200 \mathrm{ng} / \mathrm{m}^{2}$. However, whether these high Der 1 levels were a direct consequence of the earthquake is unknown, because Der 1 levels were not measured until 5 years after the earthquake. In addition, the prevalence of asthma based on the ISAAC survey did not increase despite there being an increase in the prevalence of asthma in adults with a history of residence in temporary housing after the Great East Japan Earthquake. ${ }^{9}$ The prevalence of asthma, rhinitis, and atopy in the second-grade, 7 to 8-year-old children of Ishinomaki in our research was not as high as reported by the ISAAC survey in other countries ${ }^{23-25}$ and Japan. ${ }^{26,27}$

We neither measured serum immunoglobulin $E$ (IgE) Radioallergosorbent testing (RAST) for house dust mite (HDM) nor performed skin prick test for HDM in these children. Allergic rhinitis is seasonal and often exacerbated in the fall. We established the exacerbation of allergic rhinitis by an exposure of mite allergen.

The sample size in this study was small. Entry and recruitment in the intervention test was based on parents' desire; so as a result, the intervention test was performed with a small number of participants.

Children whose bedding Der 1 levels were measured and their parents had a higher prevalence of asthma, allergic rhinitis, and atopic dermatitis than the children who did not have Der 1 level measured. In this study, the research subjects who had more severe symptoms and were more likely to volunteer to have their bedding Der 1 levels 
(A)

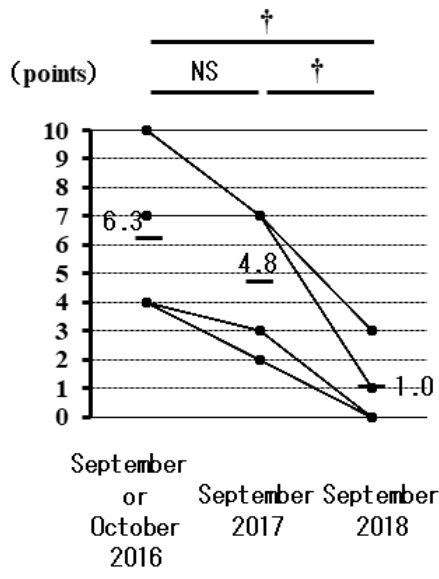

(B)

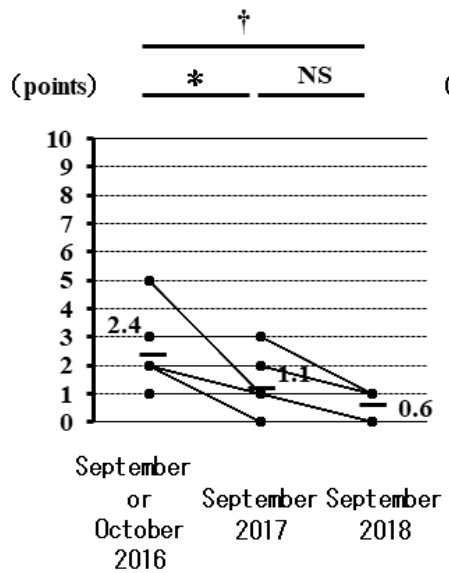

(C)

Asthma

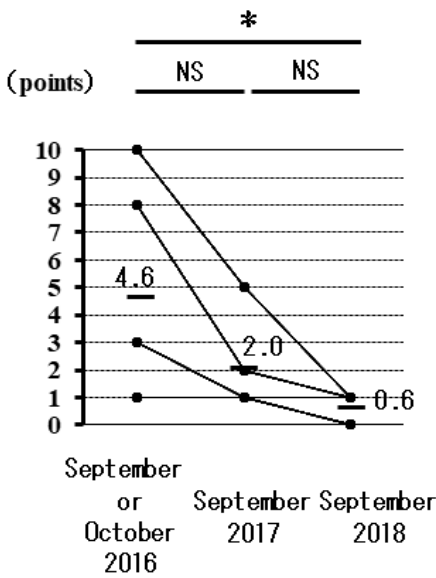

Allergic rhinitis

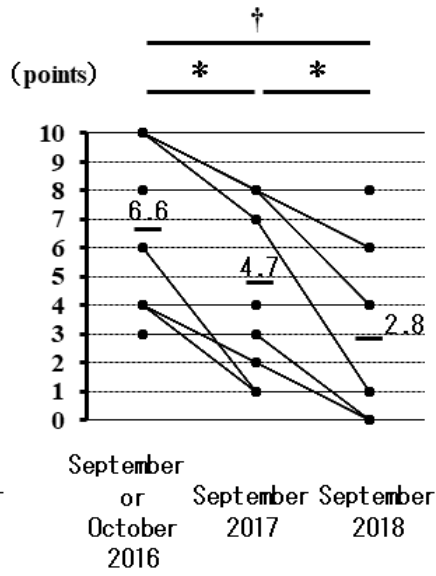

Allergic rhinitis
Atopic dermatitis

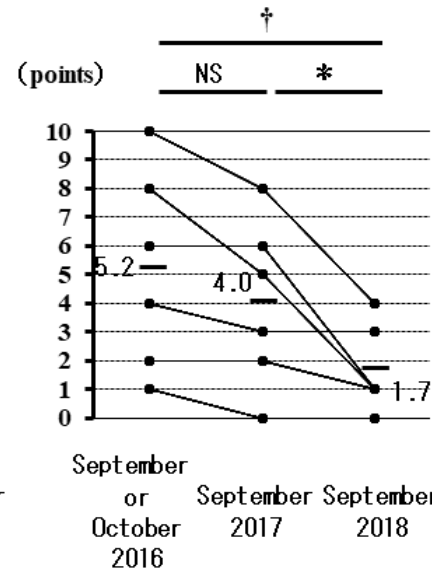

Atopic dermatitis

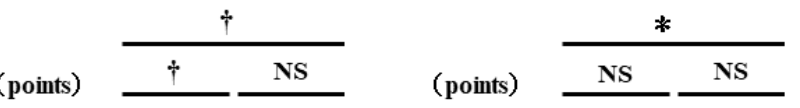

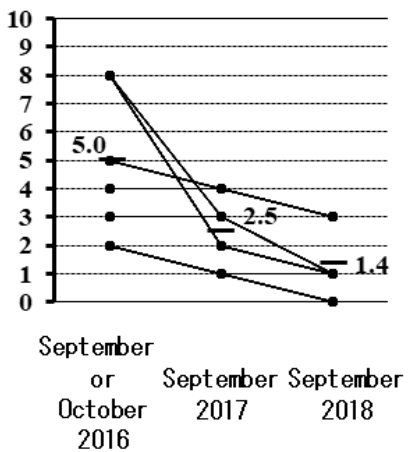

Allergic rhinitis
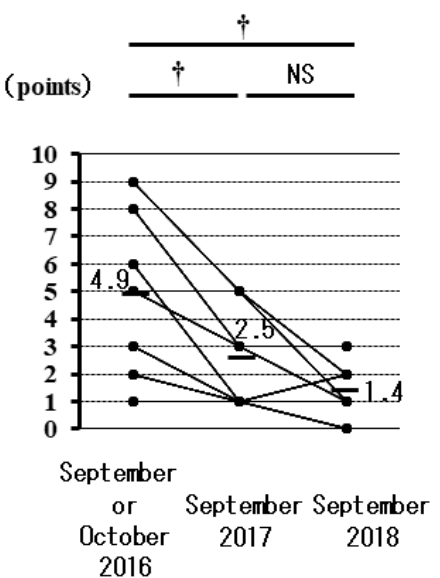

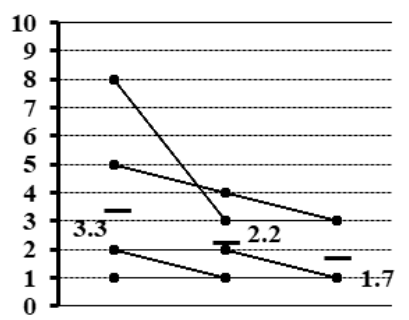

September

or September September

October $2017 \quad 2018$

2016
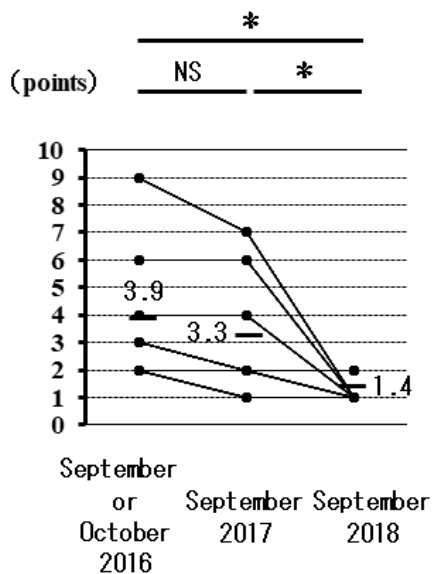

Figure 4 Changes in allergic symptom scores for asthma, allergic rhinitis, and atopic dermatitis before allergen avoidance intervention and at 1 and 2 years after initiation of allergen avoidance measures in (A) children participating in the study, (B) children's parents, and (C) children's siblings. Symptom scores from 10 to 0 are as follows: 10: I have some symptoms every day, and it is a big hindrance to my life; 9: I have some symptoms every day and I have some trouble in my life; 8: I have symptoms almost every day, but there are days when I don't really care; 7: I have symptoms almost every day, but there are many days when I don't care much; 6: I have about half of the symptoms every week; 5: I have symptoms for at least 1 day of the week; 4: there are 3 or more days of the week with symptoms but there are weeks with no symptoms; 3 : there is 1 day in a week with symptoms but there are weeks with no symptoms; 2: I have symptoms for several days in a month; 1: I may have very few symptoms in a month; 0: No symptoms at all in a month. 
measured were biased. However, both intervention and nonintervention groups did not differ significantly regarding to background factors, except that the parents of the children in intervention group had more atopic dermatitis.

We were not able to analyze the frequency of hospital visits and treatment for children with allergic symptoms. However, a questionnaire survey conducted at the time of the seminar stated that it became possible to reduce the frequency of hospital visits and the dose of therapeutic drugs for children with decreased allergic symptoms.

We used VAS for evaluating the clinical effects of allergen avoidance practices. We evaluated adult asthma using a similar VAS to evaluate decrease in asthma symptoms after antigen avoidance practices, and demonstrated that VAS was useful. ${ }^{16}$ The nonintervention group only measured the amount of mite allergen, and we did not investigate because the measurement of changes in VAS might affect the nonintervention status.

This study demonstrated that an intervention for allergen avoidance in children in Ishinomaki successfully decreased both bedding Der 1 levels and allergic symptoms. For allergen avoidance, we provided group guidance by using slides and individual guidance provided by experts. In addition, a 32-item checklist was used for each household to respond to the participants' questions because of the small number of parents and children who participated in the allergen avoidance seminars. Moreover, we believe that repeating the allergen avoidance training thrice each year contributed toward the reduced levels of mite allergen after 2 years of beginning the intervention. The nonintervention group received no information related to allergen avoidance practices, other than result reports; therefore, we do not know whether the nonintervention group conducted any allergen avoidance program. However, the Der 1 levels in the nonintervention group did not significantly change between the initial measurement in 2016 and after 1 or 2 years.

In summary, this study did not establish any relationship between increased Der 1 levels on the mattresses or futons of children in Ishinomaki and the damage caused by the Great East Japan Earthquake. However, both the Der 1 levels on the mattresses or futons of children in the intervention group and the children's symptoms of allergic diseases decreased after allergen avoidance practices. We believe that our current findings would be useful in providing advice regarding allergen avoidance measures in the event of a future earthquake.

\section{Authors' Contributions}

Naomi Tsurikisawa, Chiyako Oshikata, Maiko Watanabe, Seiichi Kobayashi, Masaru Yanai, Yoichi Kamata, Takeshi Kaneko, Shinichi Kuriyama, and Shigeo Kure conceived the idea of this study and participated in the discussion. Naomi Tsurikisawa analyzed participants' data and took responsibility for the overall guarantee of this research. Naomi Tsurikisawa, Maiko Watanabe, and Masaru Yanai negotiated with the government and schools. Naomi Tsurikisawa, Maiko Watanabe, and Chiyako Oshikata provided allergen avoidance seminars for both parents and children. Chiyako Oshikata analyzed participants' data and wrote the first draft of this paper. Kazuhiro Hashimoto, Naoki Kobayashi, Rumi Konuma, and Akiko Yamazaki helped in the seminars on allergen avoidance. Takashi Shimada measured Der 1 levels on futons or mattresses.

\section{Acknowledgments}

We thank our examination assistants Takako Oi and Hiroko Matsubara.

\section{Conflict of interest}

The authors declare no conflict of interest with respect to research, authorship, and/or publication of this paper.

\section{Funding}

2018 Ministry of Health, Labor and Welfare Administration Promotion Survey Project Cost Subsidy (Next Generation Development Basic Research Project for Overcoming Growth Diseases); Project No.: I28-Healthy-Designation-00.

\section{References}

1. Carlos WG, Cruz CD, Jamil S, Kipen H, Rose C. Mold-specific concerns associated with water damage for those with allergies, asthma, and other lung diseases. Am J Respir Crit Care Med. 2017;196:13-4. https://doi.org/10.1164/rccm.1967P13

2. Johanning E, Auger P, Morey PR, Yang CS, Olmsted E. Review of health hazards and prevention measures for response and recovery workers and volunteers after natural disasters, flooding, and water damage: Mold and dampness. Environ Health Prev Med. 2014;19:93-9. https://doi.org/10.1007/ s12199-013-0368-0

3. Shinohara N, Tokumura M, Hashimoto K, Asano K, Kawakami Y. Fungal levels in houses in the Fukushima Daiichi nuclear power plant evacuation zone after the Great East Japan Earthquake. J Air Waste Manag Assoc. 2017;67:1106-14. https://doi.org/10. 1080/10962247.2017.1330712

4. Naegele A, Reboux G, Scherer E, Roussel S, Millon L. Fungal food choices of Dermatophagoides farinae affect indoor fungi selection and dispersal. Int J Environ Health Res. 2013;23:915. https://doi.org/10.1080/09603123.2012.699029

5. Oshikata C, Watanabe M, Saito A, et al. Allergic Bronchopulmonary Mycosis due to Exposure to Eurotium herbariorum after the Great East Japan Earthquake.Prehosp Disaster Med. 2017;32:688-90. https://doi.org/10.1017/ S1049023X17006914

6. Ishikuro M, Matsubara H, Kikuya M, et al. Disease prevalence among nursery school children after the Great East Japan earthquake. BMJ Glob Health. 2017;2:e000127. https://doi. org/10.1136/bmjgh-2016-000127

7. Miyashita M, Kikuya M, Yamanaka C, et al. Eczema and asthma symptoms among schoolchildren in coastal and inland areas after the 2011 Great East Japan Earthquake: The ToMMo Child Health Study. Tohoku J Exp Med. 2015;237:297-305. https:// doi.org/10.1620/tjem.237.297

8. Yamanda S, Hanagama M, Kobayashi S, et al. The impact of the 2011 Great East Japan Earthquake on hospitalisation for respiratory disease in a rapidly aging society: A retrospective descriptive and cross-sectional study at the disaster 
base hospital in Ishinomaki. BMJ Open. 2013;3. pii:e000865. https://doi.org/10.1136/bmjopen-2012-000865

9. Oshikata C, Watanabe $M$, Ishida $M$, et al. Increase in asthma prevalence in adults in temporary housing after the Great East Japan Earthquake. Int J Disaster Risk Reduct (IJDRR). 2020; 50(9778):101696. https://doi.org/10.1016/j.ijdrr.2020.101696

10. Murray CS, Foden P, Sumner H, Shepley E, Custovic A, Simpson A. Preventing severe asthma exacerbations in children. A randomized trial of mite-impermeable bedcovers. Am J Respir Crit Care Med. 2017;196:150-8. https://doi.org/10.1164/ rccm.201609-19660C

11. Smith H, Horney D, Jones C, Goubet S, Mukhopadhyay S, Frew A. Pragmatic randomized controlled trial of an allergy intervention for children aged 6-16 with asthma and rhinitis in general practice. Clin Exp Allergy. 2016;46:1227-35. https://doi org/10.1111/cea.12781

12. Global Initiative for Asthma (GINA). Global strategy for asthma management and prevention. [cited 2019]. Available from: http://www.ginasthma.org/

13. Cloutier MM, Baptist AP, Blake KV, et al. 2020 Focused updates to the asthma management guidelines: A report from the National Asthma Education and Prevention Program Coordinating Committee Expert Panel Working Group. J Allergy Clin Immunol. 2020;146:1217-70. https://doi. org/10.1016/j.jaci.2020.10.003

14. Leas BF, D'Anci KE, Apter AJ, et al. Effectiveness of indoor allergen reduction in asthma management: A systematic review J Allergy Clin Immunol. 2018;141:1854-69. https://doi. org/10.1016/j.jaci.2018.02.001

15. Tsurikisawa N, Saito A, Oshikata C, Yasueda H, Akiyama K. Effective allergen avoidance for reducing exposure to house dust mite allergens and improving disease management in adult atopic asthmatics. J. Asthma. 2016;8:843-53. https:// doi.org/10.3109/02770903.2016.1155218

16. Tsurikisawa N, Saito A, Oshikata C, Nakazawa T, Yasueda H, Akiyama K. Encasing bedding in covers made of microfine fibers reduces exposure to house mite allergens and improves disease management in adult atopic asthmatics. Allergy Asthma Clin Immunol. 2013;9:44-53. https://doi. org/10.1186/1710-1492-9-44

17. Asher MI, Keil U, Anderson HR, et al. International Study of Asthma and Allergies in Childhood (ISAAC): Rationale and methods. Eur Respir J. 1995;8:483-91. https://doi.org/10.1183/ 09031936.95.08030483

18. Kikuya M, Miyashita M, Yamanaka C, et al. Protocol and research perspectives of the ToMMo Child Health Study after the 2011 Great East Japan Earthquake. Tohoku J Exp Med. 2015;236:123-30. https://doi.org/10.1620/tjem.236.123

19. Stewart ST, Cutler DM, Rosen AB. Comparison of trends in US health-related quality of life over the 2000s using the SF-6D, HALex, EQ-5D, and EQ-5D visual analog scale versus a broader set of symptoms and impairments. Med Care. 2014;52;1010-6. https://doi.org/10.1097/MLR.0000000000000181

20. Tovey ER, Marks GB, Matthews M, Green WF, Woolcock A. Changes in mite allergen Der $p \mathrm{I}$ in house dust following a spraying with a tannic acid/acaricide solution. Clin Exp Allergy. 1992;22:67-74. https://doi.org/10.1111/j.1365-2222.1992.tb00116.x

21. Yasueda H, Saito A, Akiyama K, et al. Estimation of Der $p$ and $\operatorname{Der} f 1$ quantities in the reference preparations of Dermatophagoides mite extracts. Clin Exp Allergy. 1994;19:10305. https://doi.org/10.1111/j.1365-2222.1994.tb02739.x

22. Bandino JP, Hang A, Norton SA. The infectious and noninfectious dermatological consequences of flooding: a field manual for the responding provider. Am J Clin Dermatol. 2015;16:399424. https://doi.org/10.1007/s40257-015-0138-4

23. Gough H, Grabenhenrich L, Reich A, et al. Allergic multimorbidity of asthma, rhinitis and eczema over 20 years in German birth cohort MAS. Ped Allergy Immunol 2015;26:431-7. https:// doi.org/10.1111/pai.12410

24. Oliveira TB, Persigo ALK, Ferrazza CC, Ferreira ENN, Veiga ABG. Prevalence of asthma, allergic rhinitis and pollinosis in a city of Brazil: A monitoring study. Allergol Immunopathol (Madr). 2020;48:537-44. https://doi.org/10.1016/j.aller.2020.03.010

25. Pols DH, Wartna JB, Moed H, Alphen El, Bohnen AM, Bindels PJE. Atopic dermatitis, asthma and allergic rhinitis in general practice and the open populations: A systematic review. Scand J Prim Health Care. 2016;34:143-50. https://doi.org/10. 3109/02813432.2016.1160629

26. Okada Y, Kumagai H, Morikawa Y, Akasawa A. Epidemiology of pediatric allergic disease in the Ogasawara Islands. Allergol Int. 2016;65:37-43. https://doi.org/10.1016/j.alit.2015.06.010

27. Futamura $M$, Ohya $Y$, Akashi $M$, et al. Age-related prevalence of allergic disease in Tokyo schoolchildren. Allergol Int. 2011;60:509-15. https://doi.org/10.2332/allergolint.10-OA-0293 